\section{Provision of female sterilization in Ribeirão Preto, São Paulo, Brazil}

\author{
Oferta da esterilização feminina \\ em Ribeirão Preto, São Paulo, Brasil
}

Elisabeth Meloni Vieira 1

Nicholas John Ford 2

\footnotetext{
${ }^{1}$ Departamento de Medicina Social, Faculdade de Medicina de Ribeirão Preto, Universidade de São Paulo, Ribeirão Preto, Brazil. 2 Department of Geography, School of Geography and Archaeology, University of Exeter, Exeter, United Kingdom.

Correspondence E. M. Vieira Departamento de Medicina Social, Faculdade de Medicina de Ribeirão Preto, Universidade de São Paulo. $A v$. dos Bandeirantes 3900 2 o andar, Ribeirão Preto, $S P$ 14049-900, Brasil. bmeloni@fmrp.usp.br
}

\section{Abstract}

Forty percent of Brazilian married women from 15 to 49 years of age have undergone surgical sterilization. The 1988 Brazilian Constitution states that all scientifically proven contraceptive methods should be available to all citizens, but it was only in 1997 that specific family planning legislation was approved. This study examines physicians' perceptions and attitudes towards the current provision of female sterilization and its legal implications, as well as women's experience with obtaining and undergoing sterilization. The study design included: (1) an investigation of the hospitals and health professionals and (2) a survey of women sterilized in combination with cesarean delivery in 1998. The survey showed they had a median of 3 living children, $60.0 \%$ had been sterilized between 30 and 39 years of age, and 61.0\% had paid for the procedure. Many women reported previous method failure and adverse effects with hormonal contraceptives. Women with less schooling and lower socioeconomic status had more children and had begun childbearing and had been sterilized at younger ages than women with more schooling and higher socioeconomic status. Inequalities related to reproduction were strongly associated with teenage pregnancy and inadequate knowledge about contraceptives.

Family Planning; Sterilization; Contraception

\section{Introduction}

Providing equal access to reproductive health is an important explicit goal for the health care system in Brazil. Ten years before the Cairo Conference, held in 1994, the Brazilian government designed the Women's Comprehensive Health Program with this aim in mind. However, many of this program's activities have never been implemented 1,2. Equal access to contraception is one key aspect of reproductive health that falls short of the desired objectives in Brazil. While upper and middle-income women can use the private health care system to access reversible contraception, lower-income women have to rely on the public health care system, in which several problems have already been detected 3 . Shortage of contraceptives and lack of properly trained health professionals are the main problems. One result of this is a clandestine medical market for contraception, which has been active for the last 20 years, creating a "culture of female sterilization" 4.

Female surgical sterilization is the most widely used contraceptive method in Brazil. According to the last Demographic and Health Survey, dated 1996, $40.0 \%$ of 15-to-49-year-old married Brazilian women have been sterilized. In São Paulo, the most developed and populous state of Brazil, provision of female sterilization has been well studied and was found to be strongly associated with cesarean sections $4,5,6$. 
Many of these tubal ligations are performed clandestinely in conjunction with cesarean sections and are paid for directly to the physicians, without being recorded in the patient's hospital record.

Until recently, surgical sterilization had ambiguous legal status in the country. The 1988 Brazilian Constitution states that family planning and all scientifically proven contraceptive methods should be available to all citizens who wish to plan their families. However, for many years the Brazilian Medical Council has not recommended that physicians perform sterilization, since they can be sued on the basis of Article 129, paragraph 3, of the country's Penal Code, which classifies as a crime any unauthorized medical procedure leading to a loss of body part or function. In addition, the Women's Comprehensive Health Program of the Ministry of Health only recommends that sterilization be performed in women over 35 years of age whose life may be at risk in case of pregnancy 7.

In 1997, new family planning legislation (Federal Act 9,263) was approved. This legislation covers several aspects of family planning and for the first time included male and female sterilization and the respective requirements for users, institutions, and physicians (Table 1). It also establishes clear guidelines for the Unified National Health System (SUS) to provide reversible contraceptives, male and female sterilization, and counseling by a multidisciplinary team. The law forbids immediate post-delivery or post-abortion female sterilization and requires a 48-day waiting period after these interventions. Sterilization can only be performed at least 60 days after the individual has expressed the wish to submit to the procedure. According to the legislation, family planning services (as other health care services) should therefore be provided as a duty of the state, and are thus free of charge, since one of the basic principles of the SUS is universal and free access to care for all citizens. Non-compliance with the legislation entails penalties (including individual imprisonment) and fines for physicians and institutions. The law entered into force after its publication in November 1997.

It was anticipated that enforcement of these legal requirements for sterilization might be problematic for two main reasons: (1) there is a financial advantage for physicians to perform female sterilization clandestinely, as indicated in previous studies 5,6 and (2) there was a question regarding the capacity of the public health care system to meet the demand for sterilization ${ }^{8}$. These concerns provide the basis for un- dertaking an investigation into the provision of female sterilization in Ribeirão Preto, São Paulo State. The city has a high cesarean rate, clearly consistent with female sterilization in the country as a whole 9 , and there was a mandate for the public health care system to enforce the legal requirements for family planning. This study sought to examine: (1) physicians' perceptions and attitudes towards the current provision of female sterilization and in particular its legal implications and (2) women's experience with obtaining and undergoing sterilization. The study thus aimed at a combined analysis of providers' and users' perspectives. The findings have been used to enhance contraceptive provision in the local public health care system.

Ribeirão Preto is located in northeast São Paulo State, Brazil. Its some 500,000 inhabitants according to the last census (http://www. ibge.gov.br, accessed on 09/Oct/2001) and is the epicenter of a region with some two million inhabitants, in terms of trade, services, and facilities, including education and health care. The city, located in one of the most developed areas of Brazil, has an economy based on the production and processing of agricultural products such as sugar cane, oranges, and beef 10 . Disease distribution is similar to that of Brazil in general, reflecting a high level of economic development along with substantial inequality in income distribution. Overall mortality reflects a combination of non-communicable and infectious diseases. The city has 12 hospitals, with an average of 4 beds per 1,000 inhabitants. One hundred percent of births are assisted by nine hospitals. Cesarean deliveries comprised $62.7 \%$ of all births in 1997 and $61.0 \%$ in 1998 11. Since 1999, the Municipal Health Department has been taking measures to enforce the new family planning legislation. Family planning-related activities comprise: (1) training of health professionals working in primary care clinics to provide family planning counseling and contraceptives, (2) the creation of a committee to supervise counseling of individuals requesting male or female sterilization, and (3) implementation of all the legal requirements in one hospital with effective provision of male and female sterilization 12,13.

\section{Methods}

The study design included two components: (1) a survey of the hospitals and health professionals and (2) a survey of women who had undergone cesarean deliveries in 1998, thus the year after enactment of the legislation. The 
specific objectives of the first component were to verify compliance with the legal requirements for female sterilization in the local hospitals, to identify knowledge among hospital personnel about the new legislation, and to explore health professionals' attitudes towards this law. The survey of women who had undergone cesareans aimed specifically to study the enforcement of legal requirements for female sterilizations performed in 1998 and to identify and characterize access to female sterilization by these women.

For the first component of the study, we collected secondary data from all nine hospitals providing obstetric care and administered 17 in-depth interviews with key informants, including physicians and health care managers, from November 1999 to October 2000. The key informants included all nine hospital managers, four gynecologists practicing in the city, two professors of gynecology and obstetrics at the local university, one representative of the local Medical Association, and the municipal manager of the Women's Comprehensive Health Program. In addition to the in-depth interview protocol, three other research instruments were developed. The first was an outline to collect hospital data and verify compliance with institutional requirements for performing sterilization. The other instruments were forms to assess the key informants' knowledge and attitudes concerning the legislation.

In the survey of women who had given birth by cesarean section in 1998, we contacted women whose names and addresses were listed in the local health authority office as having given live birth (Live Birth Data System/SINASC). Data collection, including telephone and household interviews, was conducted from July 2000 to January 2001.

Live births in local hospitals in 1998 totaled 11,059 , of which 8,440 (76.3\%) were for women residing in the city, with the remainder coming from neighboring smaller towns. A total of $4,158(49.2 \%)$ were recorded as having given birth by cesarean section. Some 2,457 (59.0\%) were contacted by telephone, 1,075 (43.7\%), and/or home visits, 1,382 (56.2\%). All women were asked two questions: did you have a cesarean birth in 1998? Did you subsequently undergo sterilization? Those who answered yes to both questions then received a questionnaire on their obstetric history, contraceptive use, and access to female sterilization.

Of all 2,457 women contacted by telephone or home visits, $12.1 \%$ (298) had been sterilized in 1998 in combination with childbirth. Of these, $5.6 \%$ (17) refused to answer the inter-
Table 1

Summary of the legal requirements for female sterilization in Brazil.

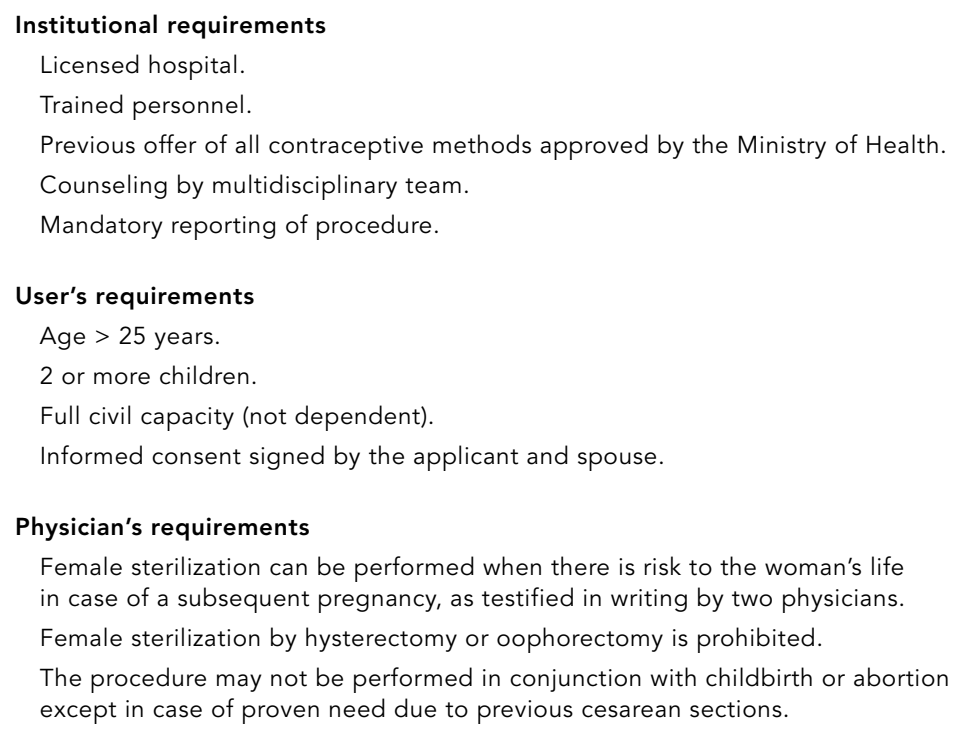

view and one was excluded due to a therapeutic hysterectomy. The questionnaire on access to female sterilization was administered faceto-face to 280 sterilized women at their homes by trained interviewers. A total of 1,701 women were not located, for several reasons: $28.9 \%$ $(1,205)$ had moved, $3.9 \%$ (163) had inconsistent addresses, $5.7 \%$ (240) had incomplete addresses, $0.12 \%$ (5) had died, and $2.1 \%$ (88) were not found at home even after three contacts. A high turnover is to be expected in the city's population, due to the seasonal sugar cane harvest, and could explain the fact that many women had moved.

By consulting patient records in the hospitals, it was possible to use data collected on $89.8 \%(1,528)$ of 1,701 women that were not located personally. These data were provided by the Hospital Data Processing Center of the Ribeirão Preto School of Medicine, University of São Paulo. Most women were 20 to 29 years of age (836, or $54.7 \%), 484$ (31.7\%) were from 30 to 39 years old, $179(11.7 \%)$ were under 19 , and $29(2.8 \%)$ were over 40 . Most of the women had their childbirth care covered by private health insurance (828, or $54.2 \%), 618(40.0 \%)$ used the SUS, and only 82 (5.4\%) paid out of pocket. 


\section{Results}

Of the nine hospitals visited, only one had less than 50 beds, six had from 50 to 150 beds, and two had more than 150 beds. The latter two hospitals have sophisticated technological facilities in terms of equipment and highly specialized staff. All nine hospitals receive private payment through health insurance or out-ofpocket from patients. Only three hospitals are licensed by the SUS to assist patients, one is a maternity hospital founded in 1998 to assist normal deliveries, and the other two were established as referral centers for complicated cases. Two of these hospitals have already been licensed to perform sterilization under Federal Act 9,263. Two private hospitals reported providing courses to prepare for labor, but do not offer education in family planning. The cesarean rates were extremely high in some private hospitals (varying from $80.2 \%$ to $90.0 \%$ in 1998). The lowest cesarean rates were in the hospitals licensed by the SUS $(12.9 \%, 36.5 \%$, and $42.7 \%$ in 1998).

\section{Knowledge}

Table 2 shows the summary of responses by key informants (medical staff) concerning knowledge on regulation of sterilization. Knowledge concerning the legislation was very poor among the respondents. Only one staff physician reported actually having read the new Federal Act. Although most were familiar with some aspects of the legislation, the most widely known item was the requirement of the husband's/ wife's signature for the procedure, and the period during which the procedure cannot be performed (post-delivery or post-abortion). The least known items concerned conditions under which the procedure can be performed, the need for two physicians to sign an approval of the procedure, and institutional requirements (such as hospital licensing, professional counseling, and the offer of all other contraceptive methods before the procedure). More than half of the informants could not inform the time period required between the patient's request for sterilization and the actual procedure. Furthermore, physicians were unfamiliar with the requirements as to minimum age, number of children, and terms to be included in the informed consent in order for female sterilization to be performed.

\section{Attitudes}

After having their knowledge about the legislation tested and after receiving information, the informants were asked if they agreed or disagreed with the terms of the law. There was generally more agreement than disagreement with the law. All informants agreed that two physicians should sign an approval for sterilization when a subsequent pregnancy would place the patient's life at risk, and that the patient should provide her informed consent while not under the effect of medication or any other conditions that could interfere in her decision. Nearly all agreed that neither hysterectomy nor oophorectomy should be performed as a means of sterilization. Only one informant stated that he neither agreed nor disagreed with the offer of all contraceptive methods before sterilization or with the signed consent (that is, he was undecided). There was some disagreement concerning the legal conditions related to age, number of children, mandatory reporting of the procedure, and hospital licensing for sterilization. However, the strongest disagreement related to the fact that the legislation does not allow sterilization to be performed in the post-delivery or post-abortion period. During the in-depth interviews, other aspects of the law were explored, such as payment "under the table" and "the package deal", two slang expressions referring to clandestine payment for sterilization. The physicians did not see themselves as part of the "sterilization problem". They felt that there is no problem with sterilization in general and failed to see its association with the abusive, excessive, and unnecessary number of cesarean sections in Brazil. Some informants came out in defense of medical practice without government interference or any other kind of regulation. The following comments were common: "This law is all wrong", "The law will never make it off paper", or "People will never accept this law".

\section{Survey of sterilized women}

\section{Socio-demographic information}

Mean age of the 280 respondents was 34.6 years (range: $24-47$ ), and some $65.0 \%$ were between 30 and 39 years of age. Most of the women $(71.4 \%)$ were married, and $20.0 \%$ lived with a partner. Only $8.5 \%$ were divorced, widows, or single. The majority, 197 (70.4\%) classified themselves as white, as compared to 44 mixedrace (15.7\%), and 38 black (13.6\%). Respondents 
Knowledge about the Act 9,263 among physicians and health care managers. Ribeirão Preto, São Paulo, Brazil, 2001.

\begin{tabular}{|c|c|c|c|}
\hline Female sterilization is only allowed in the following situation & Correct & Incorrect & Observation \\
\hline 1. Under which individual conditions can female sterilization be performed? & 4 & 10 & $\begin{array}{l}3 \text { provided } 50 \% \\
\text { correct information }\end{array}$ \\
\hline $\begin{array}{l}\text { 2. How can a woman access tubal ligation if there is a risk to her life in case } \\
\text { of a subsequent pregnancy? }\end{array}$ & 3 & 14 & \\
\hline 3. What is the period required between expression of intent and submitting to the procedure? & 5 & 12 & \\
\hline 4. What information should be stated in the informed consent form? & 4 & 9 & $\begin{array}{l}4 \text { provided } 50 \% \\
\text { correct information }\end{array}$ \\
\hline 5. During what period should tubal ligation not be performed? & 8 & 9 & \\
\hline 6. Who should sign the informed consent? & 10 & 7 & \\
\hline 7. What forms of surgical sterilization are prohibited? & 5 & 11 & $\begin{array}{l}1 \text { provided } 50 \% \\
\text { correct information }\end{array}$ \\
\hline 8. Under which situations can the intention to submit to sterilization not be considered? & 6 & 11 & \\
\hline 9. Which official records are required? & 6 & 12 & \\
\hline 10. What are the hospital requirements for performing sterilization? & 3 & 14 & \\
\hline
\end{tabular}

had an average of 8.3 years of schooling. A total of $94(33.4 \%)$ had attended school for four or more years but had not finished basic education (8 years, the equivalent of primary plus junior high school), 54 (19.2\%) had complete basic schooling but not secondary school, and 76 (27.1\%) had finished secondary school but had not finished the university. Some 28 (10.0\%) had completed a university degree, and the same proportion had finished less than four years of school. Only 4 women had never attended school. Socioeconomic status assessed by a set of questions using ABA/ABIPEME (Brazilian Association of Market Research Institutes) criteria showed that $112(40.0 \%)$ belonged to class C, as compared to $86(30.7 \%)$ class B, 50 (17.8\%) class D, and $29(10.4 \%)$ class A. Only $3(1.1 \%)$ were classified as E.

\section{Obstetric history}

Respondents reported a mean of 3.3 pregnancies (range: $1-9) .38 .5 \%$ had three pregnancies, $24.6 \%$ had two, $18.2 \%$ had four, $12.0 \%$ had five, $4.6 \%$ had six, and $10.0 \%$ had seven pregnancies. Only one woman had one and another one had nine pregnancies. The mean number of children currently alive was 3.0. Only two women $(0.7 \%)$ had one living child, $31.7 \%$ had two, $40.3 \%$ had three, $19.6 \%$ had four, and $7.5 \%$ had five or more living children. Most women reported not having had an abortion or miscarriage, but almost one-fifth $(23.0 \%)$ reported at least one interruption of pregnancy. Nearly half (48.9\%) reported a history of health problems during one or more pregnancies.

\section{Contraceptive methods: knowledge and history}

Overall awareness concerning contraceptive methods was good. All respondents had heard about oral contraceptives, and $84.0 \%$ had already used them. Nearly all of the respondents (98.6\%) knew about male condoms, and 33.0\% reported condom use by their partners. The calendar method was known to four out of five women, and nearly one out of five had already used it. Withdrawal (coitus interruptus) was identified by $76.0 \%$ of the women as a contraceptive method, and $17.0 \%$ of respondents had prior experience with it. Hormonal injections were known to $84.0 \%$ and used by $14.6 \%$ of them. Use of other contraceptive methods was negligible. A set of questions to assess the women's knowledge on contraceptives was also used; $36.4 \%$ of the respondents agreed with the statement that "all contraceptive methods affect women's health", $33.2 \%$ did not trust the pill, and $47.0 \%$ believed that sterilized women could have more children if they wished. Nearly $70.0 \%$ agreed with the statement that "condoms are not a reliable contraceptive method", and $83.0 \%$ believed the best way to have a tubal ligation was in combination with a cesarean section. Despite all this misinformation, $90.0 \%$ were aware that vasectomy does not cause impotency and $70.0 \%$ knew that vasectomy is easier to perform than female sterilization. In addition, $85.0 \%$ disagreed with the statement that "all sterilized women become frigid". This set of questions was scaled, and respondents' knowledge was classified as low 
(27.5\% of the respondents), medium (42.8\%), or high $(29.6 \%)$.

Women were also asked why they had discontinued the contraceptive method previously used. Adverse effects were cited by $42.5 \%$ of pill users and $56.0 \%$ of hormonal injection users. Some $36.5 \%$ of the women whose partners used condoms reported interference with sexual intercourse. Method failure leading to unwanted pregnancy was cited by $52.0 \%$ of the women who had used the calendar method and $40.0 \%$ of those resorting to coitus interruptus.

\section{Access to tubal ligation}

Most of the women had heard about female sterilization from a relative $(30.0 \%)$ or physician (29.6\%). Few $(6.0 \%)$ had read about the subject or learned about it on television. Approximately $15.0 \%$ had learned about contraceptive methods through friends, lectures, classes, etc. A full $70.0 \%$ had at least one relative (sister, mother, aunt, cousin, and/or niece) who was sterilized. Only 23 women $(8.2 \%)$ had not been sterilized in conjunction with childbirth itself, but afterwards (ranging from the following day to one month later). Most of the women (247, or $88.2 \%$ ) were pregnant when they made the decision to submit to sterilization. Mean age at sterilization was 32.8 years. Only 11 women (fewer than $4.0 \%$ ) were sterilized under 24 years of age, 63 (22.5\%) from 25 to 29 years, 105 (37.5\%) from 30 to 34 years, and 101 (36.1\%) over 35 years of age.

When women were asked why they had decided to submit to surgical sterilization, 157 (56.1\%) reported they were satisfied with the number of children they had, $13.9 \%$ reported they had undergone numerous cesarean sections, $12.5 \%$ reported health problems, $8.2 \%$ answered that sterilization was their preferred means of contraception, $3.9 \%$ said that they had experienced problems with other contraceptive methods, and 5.3\% reported other reasons such as age or financial problems. According to one woman, the physician claimed he could not perform the cesarean if he did not also perform a tubal ligation.

Questioned about how they had obtained the procedure, $74.7 \%$ reported having gone to the physician and requested it, $17.5 \%$ reported that the physician had stated that the woman needed the tubal ligation, and $7.0 \%$ stated that the physician said he could perform the procedure if the patient so desired. Two women reported that the sterilization had been performed without their consent.

Payment to the physician for the surgical sterilization was made by $171(61.1 \%)$ of the re- spondents; the remaining 109 (38.9\%) reported not having paid for the procedure. Among those who paid for the procedure, 50 (17.9\%) did not know or could not recall the amount of the fee. Forms of payment varied extensively, especially for women with private health insurance. One-third of the deliveries (33.3\%) followed by tubal ligation were free of charge.

When asked if they were counseled prior to the procedure, $248(88.5 \%)$ of the women reported having been counseled by the attending physician, $7(2.5 \%)$ by a nurse or social worker, and 25 (8.9\%) had received no counseling.

In order to assess the women's understanding of the tubal ligation procedure, a set of statements was read for them to agree or disagree. Regarding the first statement, "Sterilized woman cannot have more children, because the procedure is permanent", although most women $(55.8 \%)$ agreed, nearly half either disagreed (35.0\%) or did not know (9.3\%). However, most $(82.5 \%)$ knew that tubal ligation rarely fails, and $74.0 \%$ agreed that the procedure is difficult to reverse. Regarding reversibility, approximately one-third either did not know, or thought that they could become pregnant again if they wished. The level of explicit regret was very low; 266 women $(95.0 \%)$ reporting being satisfied with the procedure, $9(3.2 \%)$ reported regret, and only $5(1.7 \%)$ were dissatisfied.

\section{Association between variables}

Age at the first birth and socioeconomic status were associated with each other. While $43.2 \%$ of lower-income women had their first children between 14 and 19 years of age, only $17.4 \%$ of higher-income women started having children at this age (Table 3 ). The same trend was observed for schooling (Table 4 ). While $40.5 \%$ of women with less schooling started having children under 20 , only $9.2 \%$ of women with more schooling began having children at this age.

As a result, women with lower socioeconomic status underwent sterilization at a younger age; $36.0 \%$ of women classified as classes D or E submitted to sterilization between 25 and 29 years of age, while only $15.0 \%$ of the women classified as class A or B underwent sterilization in this same age bracket (Table 3). Knowledge on contraceptives is also associated with socioeconomic status. Only $11.4 \%$ of the women in classes D or E demonstrated adequate knowledge of contraceptive methods, as compared to $42.0 \%$ of women in classes A or B (Table 3 ). Similar results are shown in Table 4 for level of schooling. Payment for tubal ligation was 
Number of pregnancies, number of children currently alive, age at first delivery, age at sterilization, and knowledge of contraceptive methods according to socioeconomic status among 280 sterilized women who gave birth in 1998 . Ribeirão Preto, São Paulo, Brazil, 2001.

\begin{tabular}{|c|c|c|c|c|c|c|c|}
\hline \multirow[b]{2}{*}{ Number of pregnancies } & \multicolumn{2}{|c|}{ Classes D/E } & \multicolumn{2}{|c|}{ Class C } & \multicolumn{2}{|c|}{ Classes B/A } & \multirow[t]{2}{*}{$\mathbf{P}$} \\
\hline & $\mathrm{n}$ & $\%$ & $\mathrm{n}$ & $\%$ & $\mathrm{n}$ & $\%$ & \\
\hline $1-2$ & 7 & 13.2 & 26 & 23.2 & 37 & 32.2 & \\
\hline $3-4$ & 24 & 45.3 & 64 & 57.1 & 71 & 61.8 & \\
\hline $5-9$ & 22 & 41.5 & 22 & 19.7 & 7 & 6.0 & $<0.001$ \\
\hline Number of living children & $\mathrm{n}$ & $\%$ & $\mathrm{n}$ & $\%$ & $\mathrm{n}$ & $\%$ & \\
\hline $1-2$ & 7 & 13.2 & 34 & 30.4 & 50 & 43.5 & \\
\hline 3 & 16 & 30.2 & 44 & 39.2 & 53 & 46.0 & \\
\hline 4 or more & 30 & 56.6 & 34 & 30.4 & 12 & 10.5 & $<0.001$ \\
\hline Age at first delivery (years) & $n^{*}$ & $\%$ & $n^{\star \star}$ & $\%$ & $\mathrm{n}$ & $\%$ & \\
\hline $14-19$ & 22 & 43.2 & 38 & 34.2 & 20 & 17.4 & \\
\hline $20-24$ & 24 & 47.0 & 44 & 39.6 & 47 & 40.9 & \\
\hline 25 or more & 5 & 9.8 & 29 & 26.2 & 48 & 41.7 & $<0.001$ \\
\hline Age at sterilization (years) & $\mathrm{n}$ & $\%$ & $\mathrm{n}$ & $\%$ & $\mathrm{n}$ & $\%$ & \\
\hline $21-24$ & 6 & 11.3 & 2 & 1.8 & 3 & 2.6 & \\
\hline $25-29$ & 19 & 35.9 & 27 & 24.1 & 17 & 14.8 & \\
\hline $30-34$ & 17 & 32.0 & 43 & 38.4 & 45 & 39.1 & \\
\hline 35 or older & 11 & 20.8 & 40 & 35.7 & 50 & 43.4 & $<0.001$ \\
\hline Knowledge of contraceptive methods & $\mathrm{n}$ & $\%$ & $\mathrm{n}$ & $\%$ & $\mathrm{n}$ & $\%$ & \\
\hline Low & 21 & 39.6 & 35 & 31.5 & 21 & 18.2 & \\
\hline Medium & 26 & 49.0 & 52 & 46.9 & 42 & 36.6 & \\
\hline High & 6 & 11.4 & 25 & 21.6 & 52 & 42.2 & $<0.001$ \\
\hline Payment for tubal ligation & $\mathrm{n}$ & $\%$ & $\mathrm{n}$ & $\%$ & $\mathrm{n}$ & $\%$ & \\
\hline Yes & 8 & 15.1 & 67 & 59.4 & 96 & 83.5 & \\
\hline No & 45 & 84.9 & 45 & 40.6 & 19 & 16.5 & $<0.001$ \\
\hline Total & 53 & 100.0 & 112 & 100.0 & 115 & 100.0 & \\
\hline
\end{tabular}

* Missing cases $=2$

$\star \star$ Missing case $=1$.

closely associated with socioeconomic status and schooling; $83.5 \%$ of women with higher socioeconomic status paid for the procedure, as compared to only $15.0 \%$ of those with lower socioeconomic status.

An association was also found between health problems reported during pregnancy and the way women obtained sterilization. Among women whose physicians had recommended the procedure, $67.3 \%$ had reported health problems during pregnancy, while for those who requested that their physicians perform the operation, $44.5 \%$ reported health problems during gestation $(\mathrm{p}=0.015)$.

\section{Conclusions}

The central conclusion emerging from this study is that in order to understand the nature of the provision (and extremely high level) of female sterilization in Brazil, it is necessary to grasp the relationship between deficiencies in compliance with legal requirements by health care personnel and the pervasive pattern of unequal access to reproductive health care in the country.

First, in terms of explicit legislation (that is, the law as written on the books), Brazil has a comprehensive, compassionate, and well-organized set of legal regulations concerning female sterilization. However, there is a clear, per- 
Number of pregnancies, number of children currently alive, age at first delivery, and knowledge of contraceptive methods according to years of schooling among 280 sterilized women who gave birth in 1998. Ribeirão Preto, São Paulo, Brazil, 2001.

\begin{tabular}{|c|c|c|c|c|c|c|c|}
\hline \multirow[b]{2}{*}{ Number of pregnancies } & \multicolumn{2}{|c|}{8 years or fewer } & \multicolumn{2}{|c|}{9 to 11 years } & \multicolumn{2}{|c|}{12 years or more } & \multirow[t]{2}{*}{$\mathbf{P}$} \\
\hline & $\mathrm{n}$ & $\%$ & $\mathrm{n}$ & $\%$ & $\mathrm{n}$ & $\%$ & \\
\hline $1-2$ & 23 & 14.8 & 25 & 35.7 & 22 & 40.7 & \\
\hline $3-4$ & 89 & 57.0 & 39 & 55.7 & 31 & 57.5 & \\
\hline $5-9$ & 44 & 28.2 & 6 & 8.6 & 1 & 1.8 & $<0.001$ \\
\hline Number of living children & $\mathrm{n}$ & $\%$ & $n$ & $\%$ & $\mathrm{n}$ & $\%$ & \\
\hline $1-2$ & 30 & 19.2 & 33 & 47.1 & 28 & 51.9 & \\
\hline 3 & 64 & 41.0 & 27 & 38.6 & 22 & 40.7 & \\
\hline 4 or more & 62 & 39.8 & 10 & 14.3 & 4 & 7.4 & $<0.001$ \\
\hline Age at first delivery (years) & $n^{*}$ & $\%$ & $\mathrm{n}$ & $\%$ & $\mathrm{n}$ & $\%$ & \\
\hline $14-19$ & 62 & 40.5 & 13 & 18.6 & 5 & 9.2 & \\
\hline $20-24$ & 65 & 42.5 & 31 & 44.3 & 19 & 35.2 & \\
\hline 25 or more & 26 & 17.0 & 26 & 37.1 & 30 & 55.6 & $<0.001$ \\
\hline Payment for tubal ligation & $n^{\star \star}$ & $\%$ & $\mathrm{n}$ & $\%$ & $\mathrm{n}$ & $\%$ & \\
\hline Yes & 72 & 46.5 & 55 & 78.6 & 43 & 79.6 & \\
\hline No & 83 & 53.5 & 15 & 21.4 & 11 & 20.4 & $<0.001$ \\
\hline Knowledge of contraceptive methods & $\mathrm{n}$ & $\%$ & $n$ & $\%$ & $n$ & $\%$ & \\
\hline Low & 55 & 35.3 & 19 & 27.1 & 3 & 3.0 & \\
\hline Medium & 68 & 43.6 & 28 & 40.0 & 24 & 24.0 & \\
\hline High & 33 & 21.1 & 23 & 32.9 & 27 & 27.0 & $<0.001$ \\
\hline Total & 156 & 100.0 & 70 & 100.0 & 54 & 100.0 & \\
\hline
\end{tabular}

* Missing cases $=3$

$\star \star$ Missing case $=1$

sistent, and wide gulf between the letter of the law and its practice. Our findings clearly indicate that the majority of physicians are far from fully conversant with the legal requirements. Although most physicians support the legal tenets when prompted, the key point is that there is no auditing or monitoring of the law's actual enforcement in Brazil. Above all, our findings highlighted physicians' heavy aversion to those aspects of the law that seek to control and regulate their clinical practice. The main (and important) tenet of the law pertaining to sterilization, with which physicians disagree, and which they regularly flout, concerns the interdiction against performing sterilization in the immediate post-delivery period. Furthermore, it is clear that medical professionals simply do not identify with the (common) clandestine provision of sterilization and are not willing to see themselves as part of the problem.

The overall patterns in the survey's findings indicate the high level of contraceptive use in the country $(76.7 \%)$ and widespread use of female sterilization. The fact that some $70.0 \%$ of the women reported having a relative who had undergone tubal ligation shows that there is a "culture of sterilization" in the country 4.

According to this study, women with more schooling and higher socioeconomic status are more likely to have fewer pregnancies and fewer children than poorer women. They begin childbearing at a later age, have better knowledge of contraceptive methods, and are more likely to pay for tubal ligation. Unequal access to female sterilization is one of the reproductive health inequalities for Brazilian women of lower socioeconomic status, as reported previously by another study 6 . The survey results indicate that a high sterilization rate at earlier ages among women of lower socioeconomic status and with less schooling reflects obstacles and difficulties with reversible contraception. These obstacles relate to lack of information or misinformation about contraceptive 
methods, the limited range of methods offered by the public health care system, and extensive privatization of the health care sector, as some authors have already discussed 16. Reproductive health inequalities for women of lower socioeconomic status are particularly associated with teenage pregnancy and poor levels of knowledge concerning family planning methods. Osis 17 has pointed out that teenage pregnancy and female sterilization are interrelated.

The fact that the majority of women $(88.0 \%)$ who requested sterilization were counseled by the physicians who performed the surgery and were pregnant when they made their decision showed that many physicians are unaware of some ethical principles that should support such medical practice and that many women are unaware of their reproductive rights, as reported in a previous study 18 .

The study highlights the fact that the enforcement of legal regulations on family planning should include the clear and explicit dis-

\section{Resumo}

Quarenta por cento das mulheres brasileiras casadas de 15 a 49 anos de idade estão esterilizadas. A Constituição Brasileira de 1988 afirma que todos os métodos científicos de contracepção devam estar disponíveis para qualquer cidadão(ã), mas foi somente em 1997 que a regulamentação legal do planejamento familiar foi aprovada. Este estudo examinou as percepções $e$ atitudes dos médicos em relação à oferta atual da esterilização feminina e suas implicações legais, e a experiência das mulheres em obter o procedimento. O desenho do estudo compreende: (1) uma investigação dos hospitais e profissionais de saúde e (2) uma pesquisa com mulheres esterilizadas durante parto cesariano em 1998. Elas tinham em média três filhos vivos, 60,0\% foram esterilizadas entre 30 e 39 anos de idade, e 61,0\% pagaram pela laqueadura. Muitas relataram falhas de métodos e efeitos adversos com o uso de contraceptivos hormonais. Mulheres de nivel educacional e social mais baixo relataram maior paridade, começaram a ter filhos e foram esterilizadas mais jovens do que as mulheres com nível educacional e social mais alto. As desigualdades em torno da reprodução encontram-se fortemente associadas com gravidez na adolescência e baixo nível de conhecimento sobre métodos anticoncepcionais.

Planejamento Familiar; Esterilização; Anticoncepção semination of the terms of the law among health care personnel, including a discussion and understanding of the legislation and improvement in the overall quality of family planning care in Brazil 19. Training health care personnel in counseling skills and information, education, and communication could improve lower-income women's access to family planning choices. In addition, the need to improve young people's access to information on contraception reinforces the need for sex education in schools and communities.

This study's findings therefore indicate that in Brazil the gulf between the concept of sexual and reproductive health (with explicit reference to female sterilization), as expressed in the law and as practiced, results from problems in the culture of the medical profession, together with inadequacies in the provision of information on health rights, particularly for poor women.

\section{Collaborators}

E. M. Vieira elaborated the research project, designed the study, applied for funding, performed the data collection, and analyzed the data. N. J. Ford discussed the results with the researcher and analyzed part of the results.

\section{Acknowledgements}

The authors acknowledge the financial support of FAPESP (no 99/05863-8) for the development of this study. 


\section{References}

1. Costa AM. Desenvolvimento e implantação do PAISM no Brasil. In: Giffin K, Costa SH, organizadores. Questões da saúde reprodutiva. Rio de Janeiro: Editora Fiocruz; 1997. p. 319-35.

2. Osis MJD. PAISM: um marco na abordagem da saúde reprodutiva no Brasil. Cad Saúde Pública 1998; 14 Suppl 1:25-32.

3. United Nations Population Funds. Contraceptive requirements and logistics management needs in Brazil. New York: United Nations Population Fund; 1995.

4. Berquó E. Brasil, um caso exemplar: anticoncepção e partos cirúrgicos à espera de uma ação exemplar. Estudos Feministas 1993; 1:366-81.

5. Janowitz B, Higgins JE, Clopton DC, Nakamura MS, Broen ML. Access to postpartum sterilization in Southeast Brazil. Med Care 1982; 20:526-34.

6. Vieira EM, Ford NJ. The provision of female sterilization in São Paulo, Brazil: a study among lowincome women. Soc Sci Med 1996; 42:1427-32.

7. Secretaria de Estado da Saúde de São Paulo. Subprograma de saúde da mulher: planejamento familiar. v. 5. São Paulo: Grupo de Saúde da Mulher; 1986.

8. Osis MJD. Laqueadura e representações acerca da sexualidade e do papel reprodutivo [Tese de Doutorado]. São Paulo: Faculdade de Saúde Pública, Universidade de São Paulo; 2001.

9. Vieira EM. Regret after female sterilization among low-income women in São Paulo, Brasil [PhD Thesis]. Exeter: Faculty of Social Studies, University of Exeter; 1994.

10. Rocha JSY, Simões BJG, Guedes GL. Assistência hospitalar como indicador de desigualdade social. Rev Saúde Pública 1997; 31:479-87.

11. Centro de Processamento de Dados Hospitaleres. Dados sobre internações hospitalares. Ribeirão Preto: Departamento de Medicina Social, Faculdade de Medicina de Ribeirão Preto, Universidade de São Paulo; 2000.
12. Vieira EM, Gueleri W, Porto MCF, Oliveira MA, Garcia MLB, Chiavenato MT. Capacitação profissional para implementação do aconselhamento e orientação em planejamento familiar na Rede Municipal de Saúde de Ribeirão Preto. In: VI Congresso Brasileiro de Saúde Coletiva: O Sujeito na Saúde Coletiva [CD-ROM]. Rio de Janeiro: ABRASCO; 2000.

13. Gueleri W, Vieira EM, Porto MCF, Garcia MLB, Chiavenato MT. A implementação da Lei do Planejamento Familiar (9.263) no Município de Ribeirão Preto. Ciênc Saúde Colet 2000; 5:44-5.

14. Vieira EM, Badiani R, Dal Fabbro AL, Rodrigues Jr AL. Caracterísitcas do uso de métodos anticoncepcionais no Estado de São Paulo. Rev Saúde Pública 2002; 36:263-70.

15. Berquó E. Panorama atual da política de anticoncepção no SUS. Brasília: Ministério da Saúde; 2001.

16. Silver LD. Direito à saúde ou medicalização da mulher? Implicações para avaliação dos serviços de saúde. In: Giffin K, Costa SH, organizadores. Questões da saúde reprodutiva. Rio de Janeiro: Editora Fiocruz; 1999. p. 299-318.

17. Osis MJD. Esterilização e gravidez na adolscência: fatores inter-relacionados. In: Vieira EM, Fernandes MELF, Bayley P, McKay A, organizadores. Gravidez na adolescência. São Paulo: Associação Saúde da Família/Family Health International; 1998. p. 67-73.

18. Vieira EM. O arrependimento após a esterilização feminina. Cad Saúde Pública 1998; 14 Suppl 1:5968.

19. Bruce J. Fundamental elements of the quality of care: a simple framework. Stud Fam Plann 1990; 21:61-90.

Submitted on $18 /$ Jun/2003

Final version resubmitted on $06 / \mathrm{Nov} / 2003$ Approved on 10/Dec/2003 